\title{
RISKS AND THREATS OF SOCIAL NETWORKS COMMUNICATION
}

This paper focuses on social networks as a source of information and a tool for its sharing. The first part of the paper defines the theoretical background while the second part is devoted to the evaluation of research which was conducted among university students in the Czech Republic. The main aim of this research is to get a deeper understanding of how students work with information obtained from social networks and to identify the main risks and threats connected with it.

Keywords: Social Networks, Analysis, Information value, Research, Internet, Media Use.

\section{Introduction}

"Almost imperceptibly we found ourselves in a new sociotechnical era - the Hybrid Age. In this new era people and technologies merge with each other which bring a lot of unprecedented consequences, opportunities, but also requirements for each individual" [1].

Social networking has become a current issue in last ten years. During this time, it significantly changed the patterns of human behavior and many fields of human activities. Sociologists point out the changes in the form and manner of human communication - from a personal communication to an on-line, non-personal communication. The changes can be observed also from the perspective of media communication.

In general, it is possible to characterize a social network as a system of social relations or a group of people who interact with each other. Each social entity has a tendency to look for a social network and/or to create its own [2]. Social networks are specific media for spreading mass communication. Virtual social networks are a phenomenon creation of which was possible due to the development of the Internet and the World Wide Web. In its environment, the social networking service allows registered members to create their personal (and corporate) public or semipublic profiles, interact with other entities, share various types of information and data, etc. The content of a social network in the web space is not static; it is generated and edited by its users [3].

Services such as Facebook, Twitter, LinkedIn, Google+, MySpace or YouTube are some of the most famous international virtual social networks used in the Czech Republic. We can also find local social networks which usually cover only the population of one country.
According to a recent research, classic media cease to be the main source of news and information [4]. The most obvious change can be observed in the decrease of traditional printed media - newspaper. There is a trend among young people of decreasing use of newspaper and TV news coverage as the source of information in exchange for the Internet. Therefore, the Internet is becoming major news media for them [5].

The goal of this article was formulated on the assumption that social networks are used for multiple reasons - not only to be a platform for interaction but also as a source of information that recipients use for forming their decisions. Social networks complement (and to some level they replace) traditional media [6]. The way of working with the information obtained from a social media may however be different from the way that information from a traditional media is handled. The main objective of this paper is to investigate how students treat the information from social networks and whether they trust such information.

\section{Methodology}

This paper was created using descriptive research. The research describes variables that are present in the field of social networking and what the relationships between the variables are. It also provides information about specific aspects of the issue. The research consisted of the following steps:

Formulation of the research problem.

Data collection and analysis of available resources.

Analysis of the data. SWOT analysis.

Interpretation and conclusion.

\footnotetext{
* Jan Zavodny Pospisil, Lucie Sara Zavodna

Department of Applied Economics, Philosophical Faculty, Palacky University in Olomouc, Czech Republic

E-mail: jan.zavodny@upol.cz
} 
Finding the answers for five elementary research questions used was necessary in order to reach the main goal of the article. These questions are:

(A) What kind of respondents use social networks and how much time do they spend using them?

(B) What are the connections of the respondents within a social network?

(C) Are the social networks currently the primary source of information?

(D) Do the respondents trust the information?

(E) Do the respondents verify the information?

To answer these research questions, a quantitative research method - semi-structured questionnaire was used. This method was chosen with regard to the research as it was necessary to obtain individual respondents' answers.

Based on the research objectives, 12 questions were formulated forming a semi-structured questionnaire. The actual questionnaire was created in Google Docs environment and was distributed in electronic form through social networks and e-mails.

The sample of respondents was selected through typological choice, during which it is necessary to analyze a typical representative of a certain group of the population. In accordance with this, the respondents were picked among university students of the age from 19 to 30 years. The majority of respondents interviewed were $19-25$ years old $(74 \%)$. The questionnaire was submitted by 871 respondents. More than half of the respondents (68\%) were female, and the rest (32\%) were male. The research was conducted in the Czech Republic, at Tomas Bata University in Zlin and Palacky University in Olomouc. Responses were collected during February and March 2013.

\section{Results}

The questions in the questionnaire were designed to identify the behavior of respondents in the context of social networks. The first question (see Fig. 1) was finding which of the social networks the respondents use. Most respondents (96\%) have an active account on Facebook. The remaining 4\% of respondents use the

\section{The usage of virtual social media}

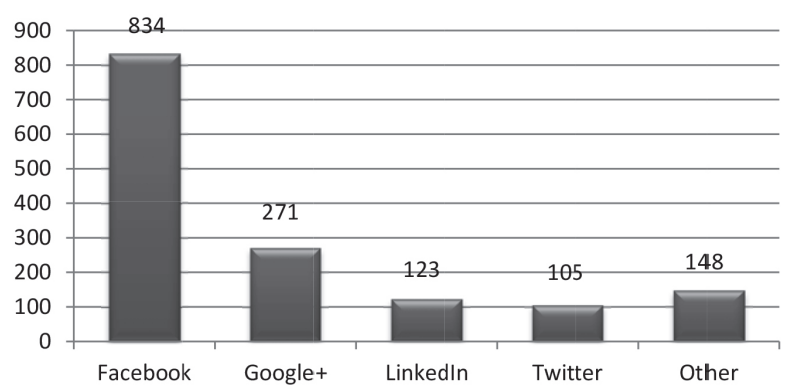

Fig. 1 Virtual social media shares among university students social network Google+. Users of social network Facebook are in most cases $(77 \%)$ at the same time also active users of other social networks, mostly (according to the rank) Google+, LinkedIn, Twitter and/or some other Czech local networks.

Regardless of the social networks used, most users (35\%) spend less than an hour a day using their favorite social network (Fig. 2). Similarly large group of users (31\%) spent 1-2 hours a day using the networks. The extensive use of social networks in the range of $2-4$ hours was confessed by $23 \%$ of the respondents. The remaining $11 \%$ of the respondents spend 4 or more hours a day using a social network.

\section{Time spent on the virtual social networks}

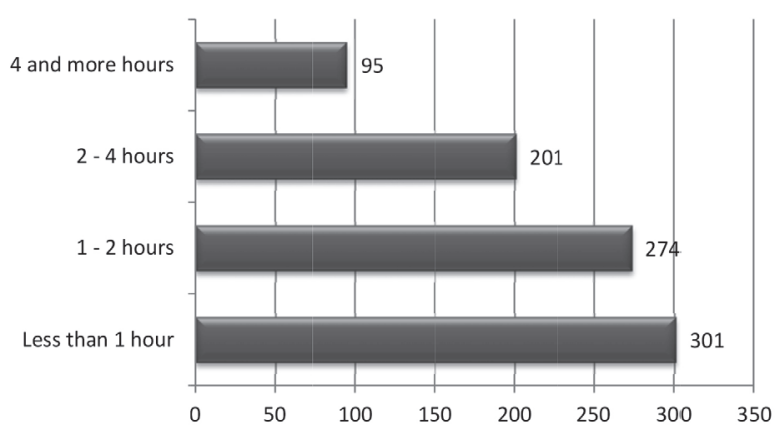

Fig. 2 Usual time spent using virtual social networks

The concern of further questioning was to uncover the connections of users within a social network and the way of making friends in the virtual network. Most respondents (61\%) are associated only with users (friends) that they know personally. In addition to friends, they know personally, $38 \%$ of respondents are also involved in various discussions (focus groups) on personal and corporate websites. Only $1 \%$ of users are not associated with any of the real friends and connections are realized only with people and groups from the virtual environment.

The following question is connected with the above-mentioned issue. It examined whether users of social networks read also the content created by unknown (possibly unrelated) people. Most users $(66 \%)$ read only posts from friends. The rest (34\%) also read posts from people who are not from their circle of friends. These posts are usually from a well-known personalities, companies, etc.

An important question was the one that examined whether the respondents verify the information on social networks published by their friends - both real and virtual friends (see Fig. 3). Answers to this closed-ended question were practically equal. While $51 \%$ of respondents claimed that they verify the information, $49 \%$ of them do not bother to do so. It is very useful to notice the connection between a source of the information (from real or virtual "friend") and an attempt to verify the information. Information from real friends is being verified by a half of the respondents. In case that information is accessed through following content created by 
people who are not respondents' real friends, such information is being verified by $54 \%$ of users.

\section{Do you verify information obtained from virtual social media?}

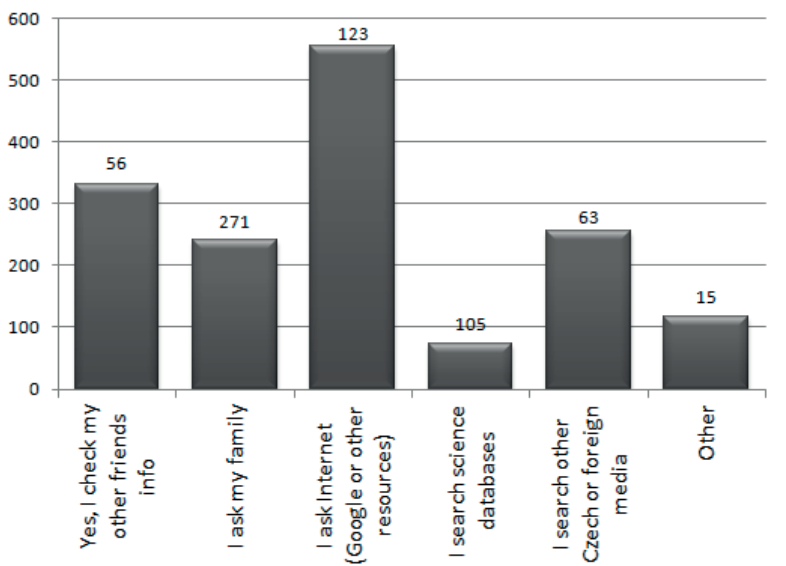

Fig. 3 Verification of information obtained from virtual social media

The following question was analyzing the personal opinion of respondents regarding a credibility of information they receive through social networks. Most respondents (79\%) consider such information to be partially trusted. Other $14 \%$ of respondents do not trust information obtained through online social networks. Only $7 \%$ of respondents trust information on social networks without any conditions as shown in Fig. 4.

\section{Is information from the social media trusted?}

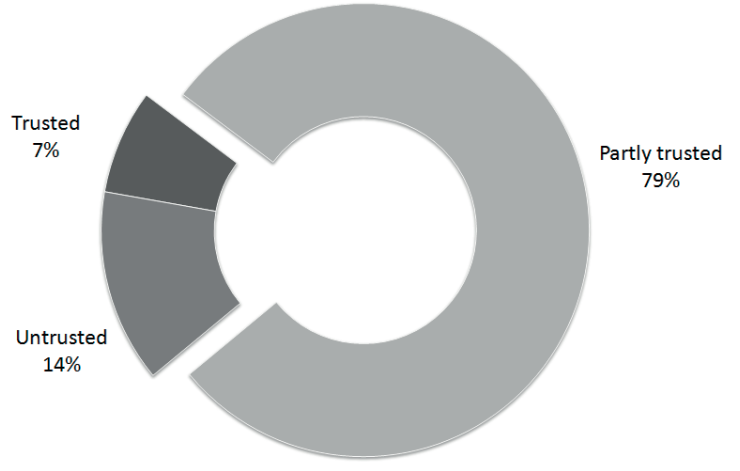

Fig. 4 Credibility of information obtained from virtual media

The research results point out the overall weaknesses of social networks. The main findings are summarized in the following chapter.

\section{Discussion: Risk and Threats of Social Networks}

The SWOT analysis of the social networks based on the research and previous findings of several authors is displayed in Table 1 below.

SWOT analysis of sharing information at social networks

Table 1

\begin{tabular}{|c|c|}
\hline Strengths & Weaknesses \\
\hline Fast information & Can be false information \\
\hline Quick overview of current & Only one side information \\
\hline situation & No internal need to verify \\
\hline Information about close friends & information \\
\hline Different platforms for & Blindness to other information \\
\hline $\begin{array}{l}\text { information, such as games, } \\
\text { competitions, etc... }\end{array}$ & Simplified information \\
\hline Opportunities & Threats \\
\hline $\begin{array}{l}\text { Educate people about risks and } \\
\text { threats }\end{array}$ & $\begin{array}{l}\text { People start to believe that } \\
\text { information }\end{array}$ \\
\hline $\begin{array}{l}\text { Educate people about social } \\
\text { media }\end{array}$ & $\begin{array}{l}\text { People will not verify } \\
\text { information }\end{array}$ \\
\hline $\begin{array}{l}\text { Educate people about value of } \\
\text { information }\end{array}$ & $\begin{array}{l}\text { People will live according that } \\
\text { information }\end{array}$ \\
\hline
\end{tabular}

This section will be dealing with threats of social networking as it is the overall focus of the paper. The biggest risks come to society from rapid dissemination of false or half-true information. And on top of that, if people attempt to verify the information through their other acquaintances or family members, this may distort the information even further. There is no need to go into details of what may cause incorrect information and how panic or hoax is created. It is not necessary since the research discovered that a large group of people do not verify the information they are given. Believing media is a general trend of a postmodern society. Once the message is released to the world, we will never find out who got it and how he/she used it.

\section{Conclusion}

While the virtual social networking is consistently more and more popular, new uses for the technology are frequently being observed. Emerging trends in social networking is the concept of "real-time web" and "location-based web". Real-time allows users to contribute content which is then broadcasted as it is being uploaded - the concept is similar to live radio and television broadcasts. Companies have begun to merge business technologies and solutions, such as cloud computing, with social networking concepts. Instead of connecting individuals based on social interest, companies are developing interactive communities that connect individuals based on shared business needs or experience. 
These new trends usually result in ability to spread information faster. There are several possibilities how to control information through the internet but at the moment there are not many people responsible for doing it. If a wrong message is spread to the world, it may cause wrong understanding of real things and their interpretation. There are several solutions to this. The government can introduce new laws, regulations or even departments for controlling information. But control is not what society wants.

As the social networks are most popular among young people, the main risks are in their wrong understanding of the role of social media. Therefore, the main focus should be on educating them about the credibility of social networks.

\section{References}

[1] KUBATOVA, J.: Preparing University Students for Hybrid Age - Suggestions for New Media Literacy Development, $5^{\text {th }}$ Intern. Conference of Education, Research and Innovation (ICERI), Madrid, 2012.

[2] VYBIRAL, Z.: Psychology of Communication (in Czech), Praha : Portal Magazine, 2005.

[3] VACHTL, P.: Web 2.0/Enterprise 2.0: Firms a Social Software (in Czech) Computerworld, 20 (14), 2009.

[4] BROLIK, T.: Without Newspapers, but with News (in Czech), Respekt, 12 (49), 2012.

[5] POSPISIL, J., ZAVODNA, L. S.: Media in Student Life: The Issue of the Introduction of Media Education into the Curricula for Secondary Schools (in Czech). Media4u, 7 (1): 25-29, 2010.

[5] ZAVODNY POSPISIL, J.: Research on the use of Social Networks as a Source and as a Mean for Sharing Information (in Czech), Media4U Magazine, No. 3, 2013. ISSN 1214-9187. 